\title{
Filovirus tropism: cellular molecules for viral entry
}

\author{
Ayato Takada* \\ Division of Global Epidemiology, Research Center for Zoonosis Control, Hokkaido University, Sapporo, Japan
}

\section{Edited by:}

Akio Adachi, University of Tokushima Graduate School, Japan

\section{Reviewed by:}

Stefan Pöhlmann, German Primate Center, Germany

Ramon Flick, BioProtection Systems Corporation, USA

Takeshi Noda, University of Tokyo, Japan

\section{${ }^{*}$ Correspondence}

Ayato Takada, Division of Global Epidemiology, Research Center for Zoonosis Control, Hokkaido

University, Kita-20 Nishi-10, Kita-ku, Sapporo 001-0020, Japan.

e-mail:atakada@czc.hokudai.ac.jp
In human and non-human primates, filoviruses (Ebola and Marburg viruses) cause severe hemorrhagic fever. Recently, other animals such as pigs and some species of fruit bats have also been shown to be susceptible to these viruses. While having a preference for some cell types such as hepatocytes, endothelial cells, dendritic cells, monocytes, and macrophages, filoviruses are known to be pantropic in infection of primates. The envelope glycoprotein (GP) is responsible for both receptor binding and fusion of the virus envelope with the host cell membrane. It has been demonstrated that filovirus GP interacts with multiple molecules for entry into host cells, whereas none of the cellular molecules so far identified as a receptor/co-receptor fully explains filovirus tissue tropism and host range. Available data suggest that the mucin-like region (MLR) on GP plays an important role in attachment to the preferred target cells, whose infection is likely involved in filovirus pathogenesis, whereas the MLR is not essential for the fundamental function of the GP in viral entry into cells in vitro. Further studies elucidating the mechanisms of cellular entry of filoviruses may shed light on the development of strategies for prophylaxis and treatment of Ebola and Marburg hemorrhagic fevers.

Keywords: filovirus, Ebola virus, Marburg virus, viral glycoprotein, receptor, tropism

\section{INTRODUCTION}

Ebola virus (EBOV) and Marburg virus (MARV), classified as biosafety level 4 agents, belong to the Family Filoviridae. Whereas MARV consists of a single species, Lake Victoria Marburgvirus, there are four distinct EBOV species, including Zaire ebolavirus (ZEBOV), Sudan ebolavirus (SEBOV), Côte d'Ivoire ebolavirus (CIEBOV), Reston ebolavirus (REBOV), and the proposed new species Bundibugyo ebolavirus (BEBOV) (Sanchez et al., 2007; Towner et al., 2008) (Figure 1 left). Among these, ZEBOV, first identified in 1976, seems to be the most virulent, killing approximately up to $90 \%$ of infected individuals, whereas REBOV, which was initially isolated from cynomolgus monkeys imported from the Philippines into the USA in 1989, is less pathogenic in experimentally infected non-human primates (Fisher-Hoch and McCormick, 1999) and has never caused lethal infection in humans (Sanchez et al., 2007).

Ebola virus and Marburg virus are filamentous, enveloped, non-segmented, single-stranded, negative-sense RNA viruses (Figure 2). The viral genome encodes seven structural proteins, nucleoprotein (NP), polymerase cofactor (VP35), matrix protein (VP40), glycoprotein (GP), replication-transcription protein (VP30), minor matrix protein (VP24), and RNA-dependent RNA polymerase (L). EBOV also expresses at least one secreted nonstructural glycoprotein (sGP). Figure 3 summarizes filovirus replication in cells. At the first step of replication, viral attachment through interaction between GP and some cellular molecules is followed by endocytosis, including macropinocytosis (Nanbo et al., 2010; Saeed et al., 2010). Subsequent fusion of the viral envelope with the host cell endosomal membrane releases the viral proteins (i.e., NP, VP35, VP30, and L) and RNA genome into the cytoplasm, the site of replication. Transcription of the negative-sense viral RNA by the viral polymerase complex (VP35 and $\mathrm{L}$ ) yields mRNAs that are translated at cellular ribosomes. During replication, full-length positive-sense copies of the viral genome are synthesized. They subsequently serve as templates for replication of negative-sense viral RNA synthesis. At the plasma membrane, NP-encapsidated full-length viral RNAs and the other viral structural proteins are assembled with VP40 and GP and incorporated into enveloped virus particles that bud from the cellsurface (Noda et al., 2006; Bharat et al., 2011). Though filoviruses show broad tissue tropism, hepatocytes, endothelial cells, dendritic cells, monocytes, and macrophages are thought to be their preferred target cells, and infection of these cells is important for hemorrhagic manifestation and immune disorders (Geisbert and Hensley, 2004).

\section{FILOVIRUS HOST RANGE}

Filoviruses are known to cause severe hemorrhagic fever in human and non-human primates, but recent studies suggest that quadrupeds are also naturally susceptible to EBOV infection (Figure 1, right). In 2008-2009, REBOV infection was confirmed for the first time in pigs in the Philippines (Barrette et al., 2009). REBOV was occasionally isolated from the samples subjected to the diagnostic investigation of multiple outbreaks of a respiratory and abortion disease syndrome in swine, which were caused by porcine reproductive and respiratory syndrome virus, common in pigs in Asia. It is speculated that REBOV became detectable, most likely due to the coinfection with this porcine virus. Although pathogenicity of these swine REBOV strains to humans, non-human primates, or even pigs remains unclear, other EBOV species (i.e., ZEBOV) was shown to cause severe respiratory disease in experimentally infected pigs (Kobinger et al., 2011). During the 2001-2003 ZEBOV outbreaks in Gabon and the Democratic Republic of the Congo (DRC), when large numbers of 


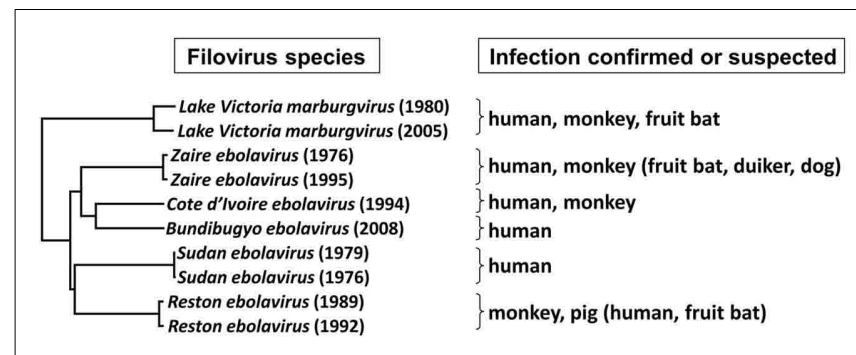

FIGURE 1 | Phylogenetic analysis of filovirus GP amino acid sequences. The phylogenetic tree was constructed using the neighbor-joining method. For construction of this tree, ten complete GP amino acid sequences were used. Infectious viruses were isolated or viral genome and/or specific antibodies were detected (in parentheses) from the animals shown on the right.

gorillas and chimpanzees were infected, the viral genome was also detected in duikers, medium-sized Bovid related to antelopes and gazelles (Leroy et al., 2004). It was also reported that several dogs in the ZEBOV-epidemic area might have been highly exposed to the virus by eating infected dead animals, as suggested by high seroprevalence, but the putative infection seems to be asymptomatic (Allela et al., 2005).

Infectious MARV was recently isolated from Egyptian fruit bats (Rousettus aegyptiacus) in Uganda, indicating that this species is susceptible to MARV infection and potentially acts as the natural reservoir of the virus (Towner et al., 2009). Phylogenetic analysis showed that viruses in the bats were closely related to those isolated from victims of the 2007 MARV outbreak in Uganda, providing the first evidence for an epidemiological link between viruses in bats and hemorrhagic fever outbreak in humans. On the other hand, EBOV has not been isolated from any bat species. During the 2001-2003 EBOV outbreaks in Gabon and DRC, however, fruit bats (Hypsignathus monstrosus, Epomops franqueti, and Myonycteris torquata) captured in the outbreak area were found to have EBOV genomic RNA and virus-specific antibodies (Leroy et al., 2005), suggesting they are potential natural reservoirs for EBOV. However, it is still unclear whether these bats continuously maintain EBOV and/or MARV and act as a potential source of filovirus transmission to humans.

It has been shown that laboratory animals, including mice and guinea pigs, are susceptible to filovirus infection. However, these animals infected with filoviruses obtained from patients normally develop a non-lethal illness, though the viruses have the ability to replicate in the animals. Guinea pigs have been used as an animal model for filovirus infection since serial passage of MARV and EBOV in the animals results in a substantial increase in lethality (Bowen et al., 1980; Hevey et al., 1997; Volchkov et al., 2000; Subbotina et al., 2010). It was also demonstrated that passages of ZEBOV through young mice resulted in the selection of variants with pathogenicity associated with mutations in viral internal genes (e.g., NP and VP40) (Bray et al., 1998; Ebihara et al., 2006). This mouse-adapted ZEBOV is highly lethal to mice. Similarly, a mouse model for MARV infection has been established (Warfield et al., 2009). Interestingly, mutations found in the GP gene of these mouse- or guinea pig-adapted viruses were not the primary factor for efficient replication in mice and guinea pigs, suggesting the importance of some other mechanisms underlying in viral replication and/or immune evasion, as shown in the pathogenesis of influenza virus (Fukuyama and Kawaoka, 2011).

\section{FILOVIRUS ENVELOPE GLYCOPROTEIN}

The fourth gene from the $3^{\prime}$ end of the filovirus genome encodes the viral envelope GP (Figure 2), which is responsible for both receptor binding and fusion of the virus envelope with the host cell membrane (Takada et al., 1997; Wool-Lewis and Bates, 1998) (Figures 3 and 4). GP is highly glycosylated with large amounts of $\mathrm{N}$ - and O-linked glycans, most of which are uniformly located in the middle one-third of the GP, designated the mucin-like region (MLR) (Yang et al., 2000; Manicassamy et al., 2007). The amino acid sequences of the MLR are highly variable among filovirus species (Sanchez et al., 1996, 1998). GP undergoes proteolytic cleavage by host proteases such as furin (Volchkov et al., 1998), which produces two subunits, GP1 and GP2, linked by a disulfide bond. The GP1 subunit mediates viral attachment, most likely through the MLR or the putative receptor binding region (RBR; Kuhn et al., 2006; Dube et al., 2009). The GP2 subunit has the heptad repeat regions required for assembling GP as a trimer. The hydrophobic fusion loop on GP2 is thought to catalyze fusion of the viral envelope and host cell membrane (Weissenhorn et al., 1998; Ito et al., 1999). Although the trigger to promote the conformational change leading to membrane fusion is not fully understood, it was recently suggested that endosomal proteolysis of EBOV and MARV GPs by cysteine proteases such as cathepsins $\mathrm{B}$ and $\mathrm{L}$ plays an important role in inducing membrane fusion (Chandran et al., 2005; Schornberg et al., 2006; Matsuno et al., 2010a). Since GP is the only viral surface GP, it is believed to have an important role in controlling the tropism and pathogenesis of filovirus infection (Takada and Kawaoka, 2001; Hoenen et al., 2006; Sanchez et al., 2007).

\section{PSEUDOTYPE VIRUS SYSTEM TO SEARCH FOR FILOVIRUS RECEPTORS/CORECEPTORS}

In the early years, studies of filoviruses were hampered by its extraordinary pathogenicity, which requires biosafety level 4 containment. To circumvent this problem, pseudotype virus systems for functional analysis of filovirus GPs have been established (Takada et al., 1997; Wool-Lewis and Bates, 1998). The systems rely on recombinant viruses (e.g., replication-competent or -incompetent vesicular stomatitis virus and retroviruses) that contain filovirus GP instead of their own GPs (Figure 5). Such pseudotype virus systems enable us to investigate cell tropism mediated by simple interaction between filovirus GP and its cellular ligands. Using such a system, it was shown that pseudotyped viruses infected primate cells more efficiently than any of the other mammalian or avian cells examined, in a manner consistent with the host range tropism of Ebola virus, and that cell-surface GPs with N-linked oligosaccharide chains might contribute to the entry of Ebola viruses, presumably acting as a specific receptor and/or cofactor for virus entry (Takada et al., 1997). Furthermore, filovirus receptor-deficient cell lines that have been used in expression cloning strategies searching for filovirus entry mediators were discovered in an early study (Wool-Lewis and Bates, 1998). Thus, 
A

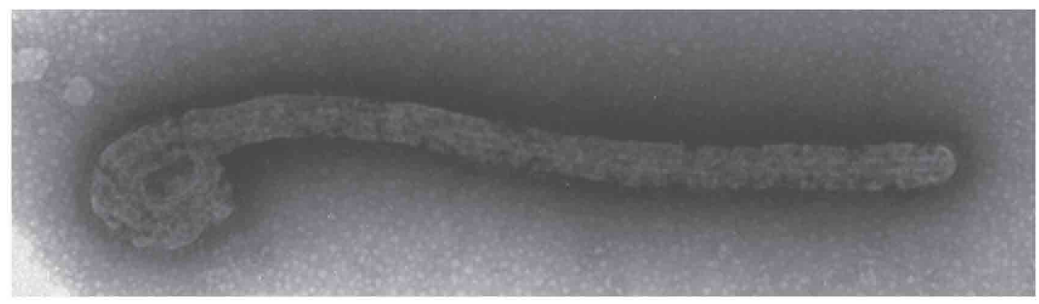

B VP30 L GP VP40

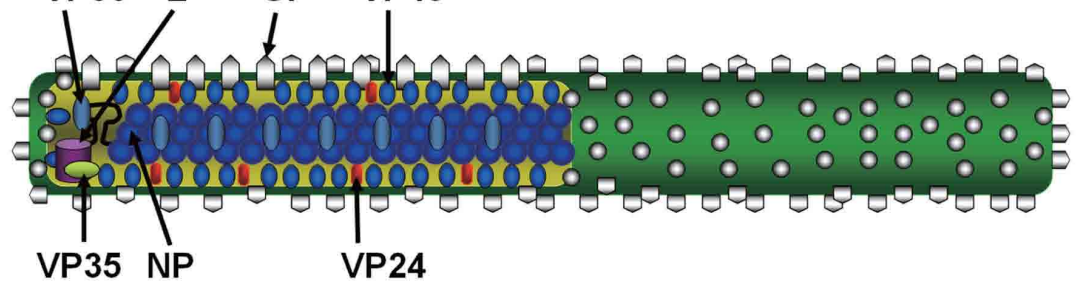

$\begin{array}{llllllll}C & \text { NP } & \text { VP35 VP40 } & \text { GP/sGP } & \text { VP30 } & \text { VP24 } & \text { L }\end{array}$

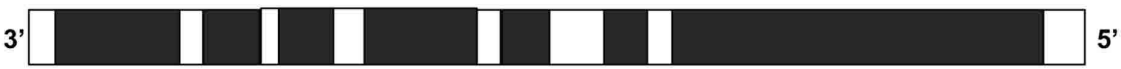

FIGURE 2 | Structure of Ebola virus particle and genome organization. Electron micrograph of Ebola virus particle (A), its diagram (B), and negative-sense genome organization (C) are shown. Viral protein names and functions are described in the text. Transcribing the glycoprotein (GP) gene produces a soluble GP (sGP). Transcriptional editing accompanied by frame shifting is required to produce full-length, membrane-anchored GP, which shares its first 295 amino acid residues with sGP.

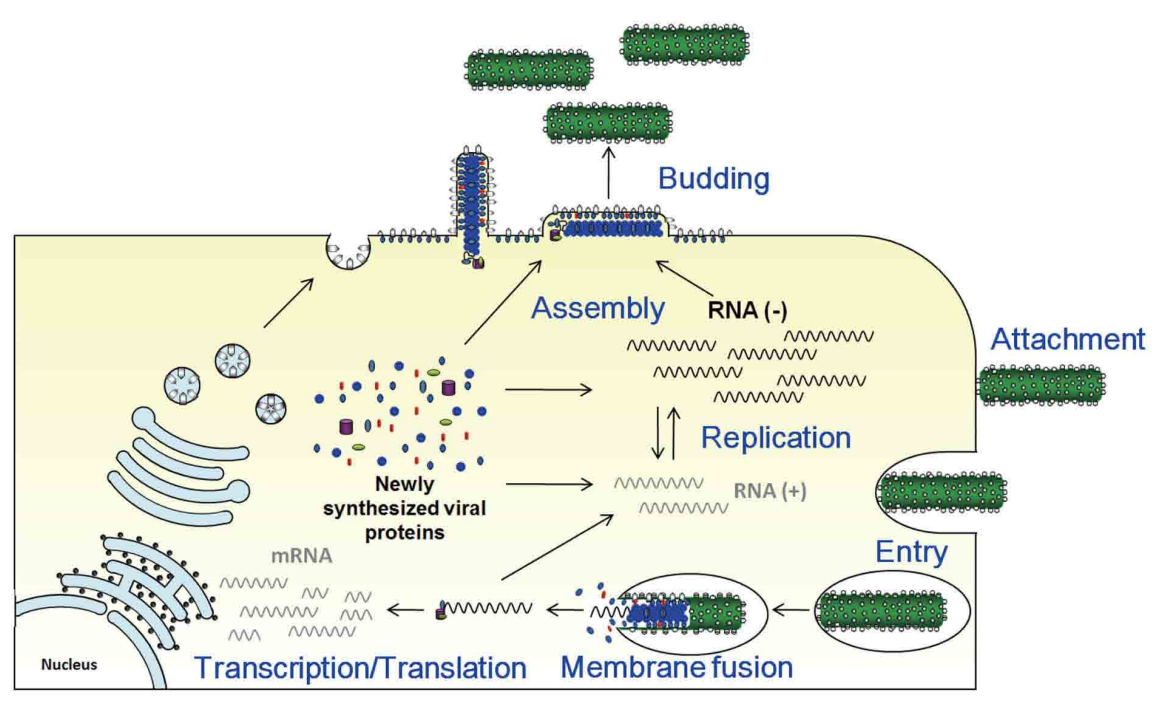

FIGURE 3 | Filovirus replication in a cell. Viral proteins involved in each step are described in the text.

pseudotype virus systems are an essential tool for recent filovirus receptor research.

\section{CELLULAR MOLECULES IDENTIFIED AS UBIOUITOUS RECEPTORS FOR FILOVIRUS ENTRY}

Although filoviruses can replicate in various tissues and cell types, the molecular mechanisms of their broad tropism remain poorly understood (Figure 6). By using an expression cloning strategy that has been used to identify several virus receptors, human folate receptor- $\alpha$ was first identified as a ubiquitous cellular cofactor that mediates infection by both MARV and ZEBOV (Chan et al., 2001). This molecule is a glycosyl-phosphatidylinositollinked protein expressed on the cell-surface. However, a human immunodeficiency virus pseudotyped with EBOV GP could not 


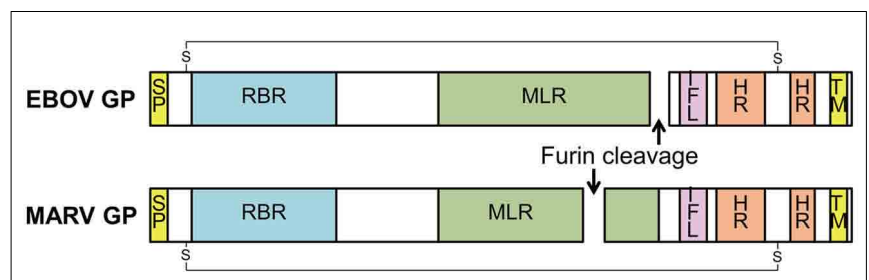

FIGURE 4 | Schematic diagram of filovirus glycoprotein. Both EBOV and MARV GPs contain signal peptides (SP), putative RBR, MLR, furin cleavage site, internal fusion loop (IFL), heptad repeat (HP), and transmembrane (TM) regions.
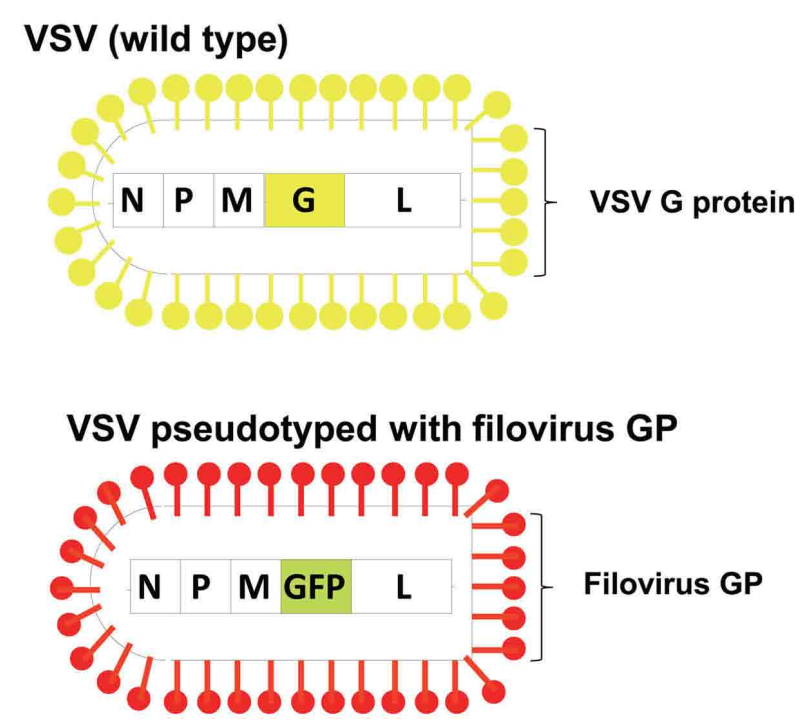

FIGURE 5 | Schematic diagram of vesicular stomatitis virus (VSV) pseudotyped with filovirus GP. The pseudotype virus relies on a recombinant virus that contains a reporter gene instead of the vira envelope protein gene responsible for receptor-binding and membrane fusion. Since filovirus glycoprotein is efficiently incorporated into VSV particles, a recombinant VSV that contains the green fluorescent protein (GFP) gene, instead of the $\mathrm{G}$ protein gene can be generated. This virus is not infectious unless the envelope protein responsible for receptor binding and membrane fusion is provided in trans.

infect T-cell lines stably expressing this protein, suggesting that folate receptor- $\alpha$ is not sufficient to mediate entry (i.e., some other molecules are required) (Simmons et al., 2003b; Sinn et al., 2003). A similar approach identified members of the Tyro3 receptor tyrosine kinase family (Axl, Dtk, and Mer) as molecules involved in cell entry of filoviruses (Shimojima et al., 2006). Expression of these family members in lymphoid cells, which are originally non-permissive to filoviruses, enhanced infection by pseudotype viruses bearing filovirus GPs on their envelopes. These molecules are widely distributed in many types of cells throughout the body, though not on lymphocytes and granulocytes (Linger et al., 2008). A more recent study demonstrated that reduction of Axl expression by RNAi treatment resulted in decreased ZEBOV entry via. macropinocytosis but had no effect on the clathrin-dependent or caveola/lipid raft-mediated endocytic mechanisms, suggesting that Axl enhances macropinocytosis (Hunt et al., 2011). However, direct interactions between these cellular molecules and the GP RBR remain to be demonstrated.

Recently, a bioinformatics approach, comparative genetics analysis, was used to screen the candidate genes involved in ZEBOV entry and T-cell immunoglobulin and mucin domain 1 (TIM-1) was identified as a candidate ZEBOV and MARV cellular receptor by correlation analysis between the gene expression profiles and permissiveness to viral infection (Kondratowicz et al., 2011). TIM1 was shown to bind to the RBR of ZEBOV GP, and ectopic TIM-1 expression in poorly permissive cells enhanced EBOV infection. In addition, reduction of cell-surface expression of TIM-1 by RNAi decreased infection of highly permissive Vero cells, which are commonly used for filovirus propagation. However, the fact that not all cell types that are naturally permissive for filoviruses express the above-mentioned molecules implies that filoviruses may utilize multiple cellular proteins for infection of a wide variety of cells. More recent studies suggest that endo/lysosomal cholesterol transporter protein Niemann-Pick C1 (NPC1) is essential for filovirus infection, providing a model of EBOV infection in which cleavage of the GP1 subunit by endosomal cathepsin removes heavily glycosylated regions to expose the putative RBR, which is a ligand for $\mathrm{NPC} 1$ and mediates membrane fusion by the GP2 subunit (Carette et al., 2011; Côté et al., 2011). Available data indicate that the cellular tropism of filoviruses does not necessarily match the distribution of any cellular molecules so far identified. Importantly, it remains elusive whether these molecules act as functional receptors that mediate both viral attachment and membrane fusion or as so-called co-receptors whose interaction with viral GP is required only for membrane fusion.

\section{MUCIN-LIKE REGION}

Both MARV and EBOV GPs contain both N- and O-linked carbohydrate chains with different terminal sialylation patterns that seem to depend on the virus strains and cell lines used for their propagation. The MLR contains a number of potential N- and Olinked glycosylation sites as mentioned above. Though the MLR is found in all known filovirus GPs, its highly variable amino acid sequences and sugar chain structure suggest different GP properties among filovirus species. Interestingly, it is well documented that deletion of the MLR does not affect the fundamental function of GP in viral entry into cells in vitro, as indicated by the observation that pseudotyped viruses bearing GP lacking the MLR infect primate epithelial cells (e.g., Vero E6 cells) similarly or rather more efficiently than viruses with wild-type GP (Simmons et al., 2002; Takada et al., 2004; Matsuno et al., 2010a). According to the crystal structure of ZEBOV GP in its trimeric, prefusion conformation, the MLR may restrict access of the putative RBR to virus receptors (Lee et al., 2008). Thus, pseudotyped viruses bearing MLR-deletion mutant GP have often been used for approaches to identify filovirus-specific receptors (Shimojima et al., 2006; Kondratowicz et al., 2011). However, the MLR plays an important role in filovirus entry into preferred target cells such as endothelial cells, hepatocytes, and antigen-presenting cells, whose infection is likely involved in tropism and pathogenesis of filoviruses, as described below. 

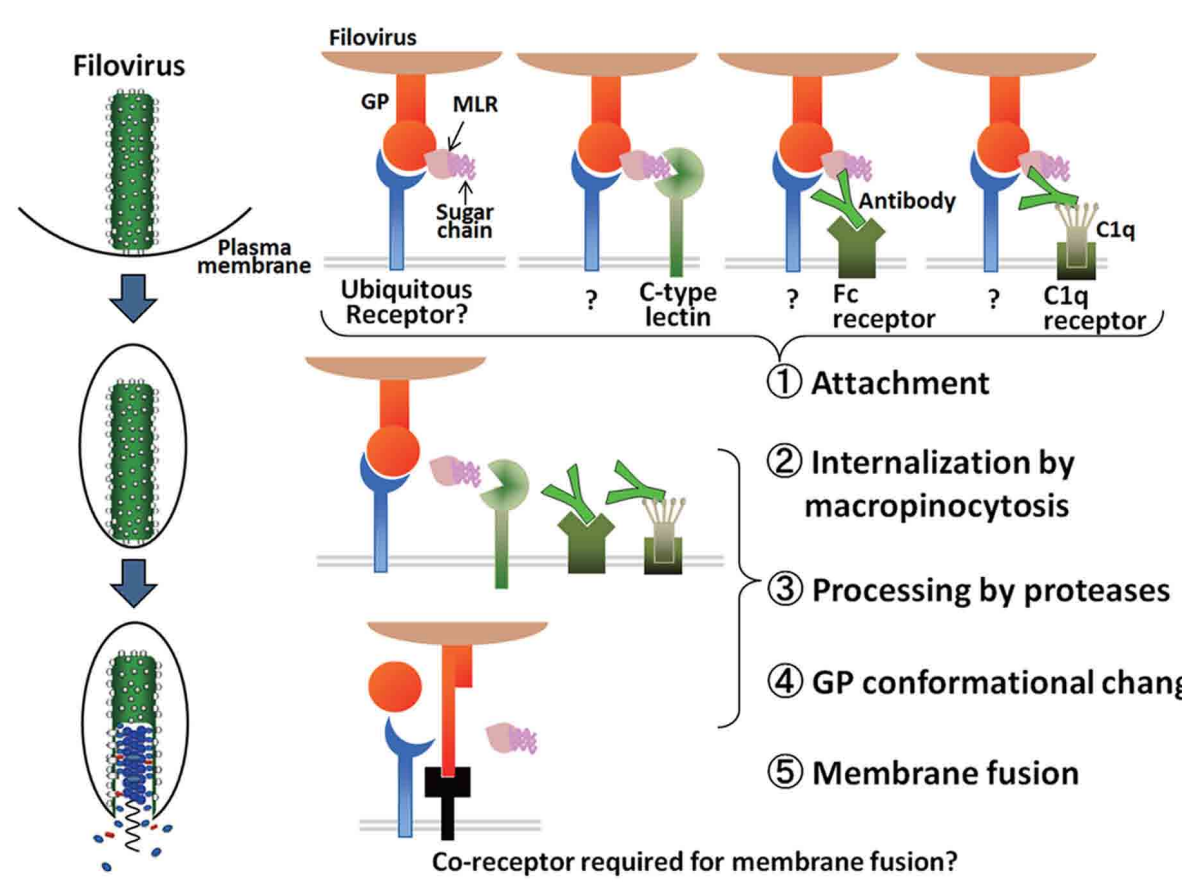

(1) Attachment

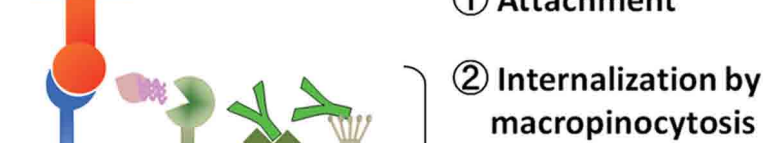
macropinocytosis

(3) Processing by proteases

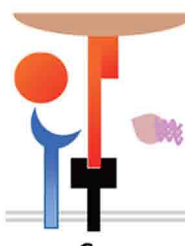

(4) GP conformational change

(5) Membrane fusion

FIGURE 6 | Proposed models of filovirus entry into cells. Virus particles attach to the cell-surface through the interaction between GP and some cellular molecules (e.g., putative ubiquitous receptors, C-type lectins). Following virus uptake and trafficking to late endosomes, GP is cleaved by cellular proteases such as cathepsins to remove heavily glycosylated regions including the MLR and expose the RBR of GP1. Binding of cleaved GP1 to a coreceptor (e.g., NPC1) might be necessary for the GP conformational change leading to membrane fusion.

\section{C-TYPE LECTINS AND THE MLR}

C-type lectins are a family of $\mathrm{Ca}^{2+}$-dependent carbohydraterecognition proteins that play crucial roles in innate immunity. It has been demonstrated that membrane-anchored cellular C-type lectins facilitate filovirus infection in vitro by binding to glycans focused on the MLR (Figure 6). The asialoglycoprotein receptor, a C-type lectin found exclusively in hepatocytes, initially proposed as a receptor for Marburg virus (Becker et al., 1995), recognizes GPs displaying $\mathrm{N}$-linked sugar chains with terminal galactose residues on the GP molecule and enhances filovirus infectivity. It was subsequently shown that carbohydrate chains on filovirus GP, especially on the MLR, are recognized by other cellular C-type lectins such as dendritic cell- and liver/lymph node-specific ICAM-3-grabbing non-integrin (DC/L-SIGN) (Alvarez et al., 2002; Lin et al., 2003; Simmons et al., 2003a; Marzi et al., 2004; Gramberg et al., 2008), human macrophage galactose-type C-type lectin (hMGL) (Takada et al., 2004; Matsuno et al., 2010a), and liver and lymph node sinusoidal endothelial cell C-type lectin (LSECtin) (Gramberg et al., 2005; Dominguez-Soto et al., 2007; Powlesland et al., 2008). Though these C-type lectins show different specificities, depending on the structures of target glycans, and thus MLR may not be the only binding site for the lectins, all have been reported to promote filovirus entry. It should be noted that C-type lectins enhance filovirus infectivity when expressed on the target cell-surface, but are unlikely to act as functional receptors mediating both attachment and membrane fusion (Simmons et al., 2003a; Marzi et al., 2007; Matsuno et al., 2010b). The fact that interaction between the GP MLR and C-type lectins is not essential for viral entry into cells lacking C-type lectins (e.g., Vero E6 cells) may also suggest that C-type lectins facilitate viral attachment but not infectious entry.

Hepatocytes, endothelial cells, dendritic cells, monocytes, and macrophages, all of which express C-type lectins, are thought to be the preferred target cells of filoviruses (Takada and Kawaoka, 2001; Geisbert and Hensley, 2004; Hoenen et al., 2006). Indeed, primary macrophage and dendritic cell cultures transduced for C-type lectin expression greatly increased their susceptibility to virus infection (Simmons et al., 2003a; Marzi et al., 2007). While C-type lectins do not directly mediate filovirus entry, their pattern of expression in vivo and their ability to enhance infection indicate that C-type lectins can play an important role in filovirus transmission and tissue tropism. Thus, increased infection of these cells might be directly involved in the pathogenesis of filoviruses. Accordingly, it was shown that soluble mannose-binding C-type lectin played a role in protection from lethal Ebola virus infection in a mouse model (Michelow et al., 2011). It should be noted that the ability to utilize the C-type lectins (i.e., DC-SIGN and hMGL) to promote cellular entry was correlated with the different pathogenicities among filoviruses (Takada et al., 2004; Marzi et al., 2006; Matsuno et al., 2010a). Interestingly, the MLR amino acid sequence does not seem to be the primary factor contributing to the difference (Marzi et al., 2006; Matsuno et al., 2010a; Usami et al., 2011). Although there might be some distinct mechanisms of entry between MARV and EBOV (Chan et al., 2000), the similarity of tissue tropism and pathological features of infection between these viruses suggests that C-type lectins are one of 
the important molecules, likely as attachment factors, for filovirus entry into cells, and that they are directly involved in filovirus tropism at the cellular level.

\section{ANTIBODY-DEPENDENT ENHANCEMENT AND EPITOPES ON THE MLR}

In addition to the common receptor/co-receptor-dependent mechanism of cellular attachment and membrane fusion, some viruses utilize antiviral antibodies for their efficient entry into target cells (Takada and Kawaoka, 2003). This mechanism is known as antibody-dependent enhancement (ADE) of viral infection. Filoviruses utilize virus-specific antibodies for their entry into cells in vitro through interaction between anti-GP antibodies and the cellular $\mathrm{Fc}$ receptor $(\mathrm{FcR})$ or complement component $\mathrm{Clq}$ and its ligand, which likely promotes viral attachment to cells (Takada et al., 2001, 2003a, 2007; Nakayama et al., 2011) (Figure 6). FcR are expressed exclusively on the cells of the immune system such as monocytes/macrophages, neutrophils, B-cells, and granulocytes (Fanger and Guyre, 1992), whereas C1q ligands have been identified in most mammalian cells (Eggleton et al., 1998; Nicholson-Weller and Klickstein, 1999), suggesting a ubiquitous mechanism for ADE of filovirus infection.

By using GP-specific monoclonal antibodies, several epitopes recognized by ADE antibodies were identified and these epitopes were mostly located in the MLR of the GP1 subunit (Takada et al., 2007; Nakayama et al., 2011). It should be noted that neutralizing antibodies appear to recognize different epitopes that are not located on the MLR (Takada et al., 2003b; Lee et al., 2008). As reflected by the high variability of the MLR amino acid sequences and limited overall cross-reactivity of anti-sera among filovirus species (i.e., ZEBOV, SEBOV, CIEBOV, BEBOV, REBOV, and MARV), ADE activities of the anti-sera to GP are virus-species-specific (Takada et al., 2001, 2007; Nakayama et al., 2010). Interestingly, potential viral pathogenicity is correlated with the ability to induce ADE antibodies, suggesting the possible contribution of ADE to different pathogenicity between filoviruses (Takada et al., 2001; Nakayama et al., 2011). More importantly, the demonstration of ADE of filovirus infection raises fundamental questions about the development of GP-based vaccines and the use of anti-GP antibodies for passive immunization.

Recently, GP has been used for viral vector-based or DNA vaccines that were shown to protect animals effectively. Replicationincompetent adenovirus expressing GP, a replication-competent vesicular stomatitis virus expressing GP, and a recombinant paramyxovirus expressing GP have been shown to protect nonhuman primates from lethal infections of filoviruses (Sullivan

\section{REFERENCES}

Allela, L., Boury, O., Pouillot, R., Délicat, A., Yaba, P., Kumulungui, B., Rouquet, P., Gonzalez, J. P., and Leroy, E. M. (2005). Ebola virus antibody prevalence in dogs and human risk. Emerging Infect. Dis. 11, 385-390.

Alvarez, C. P., Lasala, F., Carrillo, J., Muñiz, O., Corbí, A. L., and Delgado, R. (2002). C-type lectins DC-SIGN and L-SIGN mediate cellular entry by Ebola virus in cis and in trans. J. Virol. 76, 6841-6844.

Barrette, R. W., Metwally, S. A., Rowland, J. M., Xu, L., Zaki, S. R., Nichol, S. T., Rollin, P. E., Towner, J. S., Shieh, W. J., Batten, B., Sealy, T. K., Carrillo, C., Moran, K. E., Bracht, A. J., Mayr, G. A., Sirios-Cruz, M., Catbagan, D. P., Lautner, E. A., Ksiazek, T. G., White, W. R., and McIntosh, M. T. (2009). Discovery of swine as a host

et al., 2000, 2003; Jones et al., 2005; Bukreyev et al., 2007; Feldmann et al., 2007). It should be noted that these vaccines potentially induce cytotoxic cellular response (i.e., CD8+ T lymphocytes) as well as antibody production, suggesting that activating cytotoxic T-cells is a key protective mechanism (Olinger et al., 2005; Sullivan et al., 2006; Reed and Mohamadzadeh, 2007). Since cytotoxic T-cell response cannot be fully induced by immunization with non-replicative protein antigens such as inactivated virus and subunit vaccines, viral vector-based, or DNA vaccines may be promising in preventing filovirus infection.

\section{CONCLUSION}

All enveloped viruses initiate infection by attaching to host cells followed by membrane fusion via interaction between viral surface proteins and receptor/co-receptor molecules on target cells, and this interaction is often a key determinant controlling viral tissue tropism and/or host range. As described above, it has been demonstrated that filoviruses utilize multiple molecules for their entry into cells. However, it remains elusive whether these molecules serve as functional receptors mediating both viral attachment and membrane fusion or play independent roles as either attachment receptors or fusion receptors. More importantly, none of the cellular molecules identified so far explains filovirus tissue tropism and host range reasonably. It might also be hypothesized that filoviruses do not use a single common receptor to infect a broad range of cells and, unlike many other viruses, may not need a "specific" receptor. Although the overall tropism and pathogenicity of filoviruses is controlled by multiple host cell factors (e.g., interactions with the host immune system), further studies aimed at identification of cellular molecules interacting with GP are needed to fully understand the mechanisms of cellular entry of filoviruses, and may shed light on the development of strategies for prophylaxis and treatment of Marburg and Ebola hemorrhagic fevers.

\section{ACKNOWLEDGMENTS}

I thank Kim Barrymore for editing the manuscript. This work was supported by the Takeda Science Foundation, and done within the framework of the Japan Initiative for Global Research Network on Infectious Diseases (J-GRID) and the Global COE Program "Establishment of International Collaboration Centers for Zoonosis Control" of the Ministry of Education, Culture, Sports, Science, and Technology (MEXT), Japan. The work was further supported by a Grant-in-aid from the Ministry of Health, Labor, and Welfare, Japan.

for the Reston ebolavirus. Science 325 204-206.

Becker, S., Spiess, M., and Klenk, H. D. (1995). The asialoglycoprotein receptor is a potential liver-specific receptor for Marburg virus. J. Gen. Virol. 76, 393-399.

Bharat, T. A., Riches, J. D., Kolesnikova, L., Welsch, S., Krähling, V., Davey, N., Parsy, M. L., Becker, S., and Briggs, J. A. (2011). Cryo-electron tomography of Marburg virus particles and their morphogenesis within infected cells. PLoS Biol. 9, e1001196. doi:10.1371/journal.pbio.1001196

Bowen, E. T., Platt, G. S., Lloyd, G., Raymond, R. T., and Simpson, D. I. (1980). A comparative study of strains of Ebola virus isolated from southern Sudan and northern Zaire in 1976. J. Med. Virol. 6, 129-138. 
Bray, M., Davis, K., Geisbert, T., Schmaljohn, C., and Huggins, J. (1998). A mouse model for evaluation of prophylaxis and therapy of Ebola hemorrhagic fever. J. Infect. Dis. 178, 651-661.

Bukreyev, A., Rollin, P. E., Tate, M. K., Yang, L., Zaki, S. R., Shieh, W. J., Murphy, B. R., Collins, P. L., and Sanchez, A. (2007). Successful topical respiratory tract immunization of primates against Ebola virus. $J$. Virol. 81, 6379-6388.

Carette, J. E., Raaben, M., Wong, A. C., Herbert, A. S., Obernosterer, G., Mulherkar, N., Kuehne, A. I., Kranzusch, P. J., Griffin, A. M., Ruthel, G., Dal Cin, P., Dye, J. M., Whelan, S. P., Chandran, K., and Brummelkamp, T. R. (2011). Ebola virus entry requires the cholesterol transporter Niemann-Pick C1. Nature 477, 340-343.

Chan, S. Y., Empig, C. J., Welte, F. J., Speck, R. F., Schmaljohn, A., Kreisberg, J. F., and Goldsmith, M. A. (2001). Folate receptor-alpha is a cofactor for cellular entry by Marburg and Ebola viruses. Cell 106, 117-126.

Chan, S. Y., Speck, R. F., Ma, M. C., and Goldsmith, M. A. (2000). Distinct mechanisms of entry by envelope glycoproteins of Marburg and Ebola (Zaire) viruses. J. Virol.74, 4933-4937.

Chandran, K., Sullivan, N. J., Felbor, U., Whelan, S. P., and Cunningham, J. M. (2005). Endosomal proteolysis of the Ebola virus glycoprotein is necessary for infection. Science 308, 1643-1645.

Côté, M., Misasi, J., Ren, T., Bruchez, A., Lee, K., Filone, C. M., Hensley, L., Li, Q., Ory, D., Chandran, K., and Cunningham, J. (2011). Small molecule inhibitors reveal Niemann-Pick C1 isessential for Ebola virus infection. Nature 477, 344-348.

Dominguez-Soto, A., AragonesesFenoll, L., Martin-Gayo, E., Martinez-Prats, L., Colmenares, M., Naranjo-Gomez, M., Borras, F. E., Munoz, P., Zubiaur, M., Toribio, M. L., Delgado, R., and Corbi, A. L. (2007). The DC-SIGN-related lectin LSECtin mediates antigen capture and pathogen binding by human myeloid cells. Blood 109, 5337-5345.

Dube, D., Brecher, M. B., Delos, S. E., Rose, S. C., Park, E. W., Schornberg, K. L., Kuhn, J. H., and White, J. M. (2009). The primed Ebolavirus glycoprotein (19-kilodalton GP1,2): sequence and residues critical for host cell binding. J. Virol. 83, 2883-2891.
Ebihara, H., Takada, A., Kobasa, D., Jones, S., Neumann, G., Theriault, S., Bray, M., Feldmann, H., and Kawaoka, Y. (2006). Molecular determinants of Ebola virus virulence in mice. PLoS Pathog. 2, e73. doi:10.1371/journal.ppat.0020073

Eggleton, P., Reid, K. B., and Tenner, A. J. (1998). Clq - how many functions? How many receptors? Trends Cell Biol. 8, 428-431.

Fanger, M. W., and Guyre, P. M. (1992). "Fc receptors," in Encyclopedia of Immunology, eds I. M. Roitt and P. J. Delves (San Diego: Academic Press), 544-549.

Feldmann, H., Jones, S. M., DaddarioDiCaprio, K. M., Geisbert, J. B., Ströher, U., Grolla, A., Bray, M., Fritz, E. A., Fernando, L., Feldmann, F., Hensley, L. E., and Geisbert, T. W. (2007). Effective post-exposure treatment of Ebola infection. PLoS Pathog. 3, e2. doi:10.1371/journal.ppat.0030002

Fisher-Hoch, S., and McCormick, J. (1999). Experimental Filovirus infections. Curr. Top. Microbiol. Immunol. 235, 117-143.

Fukuyama, S., and Kawaoka, Y. (2011). The pathogenesis of influenza virus infections: the contributions of virus and host factors. Curr. Opin. Immunol. 23, 481-486.

Geisbert, T. W., and Hensley, L. E. (2004). Ebola virus: new insights into disease etiopathology and possible therapeutic interventions. Expert Rev. Mol. Med. 6, 1-24.

Gramberg, T., Hofmann, H., Möller, P., Lalor, P. F., Marzi, A., Geier, M., Krumbiegel, M., Winkler, T., Kirchhoff, F., Adams, D. H., Becker, S., Münch, J., and Pöhlmann, S. (2005). LSECtin interacts with filovirus glycoproteins and the spike protein of SARS coronavirus. Virology 340, 224-236.

Gramberg, T., Soilleux, E., Fisch, T., Lalor, P. F., Hofmann, H., Wheeldon, S., Cotterill, A., Wegele, A., Winkler, T., Adams, D. H., and Pöhlmann, S. (2008). Interactions of LSECtin and DC-SIGN/DC-SIGNR with viral ligands: differential $\mathrm{pH}$ dependence, internalization and virion binding. Virology 373, 189-201.

Hevey, M., Negley, D., Geisbert, J., Jahrling, P., and Schmaljohn, A. (1997). Antigenicity and vaccine potential of Marburg virus glycoprotein expressed by baculovirus recombinants. Virology 239, 206-216.

Hoenen, T., Groseth, A., Falzarano, D., and Feldmann, H. (2006). Ebola virus: unravelling pathogenesis to combat a deadly disease. Trends Mol. Med. 12, 206-215.

Hunt, C. L., Kolokoltsov, A. A., Davey, R. A., and Maury, W. (2011) The Tyro3 receptor kinase $\mathrm{Axl}$ enhances macropinocytosis of Zaire ebolavirus. J. Virol. 85, 334-347.

Ito, H., Watanabe, S., Sanchez, A., Whitt, M., and Kawaoka, Y. (1999). Mutational analysis of the putative fusion domain of Ebola virus glycoprotein. J. Virol. 73, 8907-8912.

Jones, S. M., Feldmann, H., Ströher, U., Geisbert, J. B., Fernando, L., Grolla A., Klenk, H. D., Sullivan, N. J., Volchkov, V. E., Fritz, E. A., Daddario, K. M., Hensley, L. E., Jahrling, P. B., and Geisbert, T. W. (2005). Live attenuated recombinant vaccine protects nonhuman primates against Ebola and Marburg viruses. Nat. Med. 11, 786-790.

Kobinger, G. P., Leung, A., Neufeld, J., Richardson, J. S., Falzarano, D., Smith, G., Tierney, K., Patel, A., and Weingartl, H. M. (2011). Replication, pathogenicity, shedding, and transmission of Zaire ebolavirus in pigs. J. Infect. Dis. 204, 200-208.

Kondratowicz, A. S., Lennemann, N. J., Sinn, P. L., Davey, R. A., Hunt, C L., Moller-Tank, S., Meyerholz, D. K., Rennert, P., Mullins, R. F., Brindley, M., Sandersfeld, L. M., Quinn, K., Weller, M., McCray, P. B. Jr. Chiorini, J., and Maury, W. (2011). T-cell immunoglobulin and mucin domain 1 (TIM-1) is a receptor for Zaire ebolavirus and Lake Victoria Marburg virus. Proc. Natl. Acad. Sci. U.S.A. 108, 8426-8431.

Kuhn, J. H., Radoshitzky, S. R., Guth, A. C., Warfield, K. L., Li, W., Vincent, M. J., Towner, J. S., Nichol, S. T., Bavari, S., Choe, H., Aman, M. J., and Farzan, M. (2006). Conserved receptor-binding domains of Lake Victoria Marburg virus and Zaire ebolavirus bind a common receptor. J. Biol. Chem.281, 15951-15958.

Lee, J. E., Fusco, M. L., Hessell, A. J., Oswald, W. B., Burton, D. R., and Saphire, E. O. (2008). Structure of the Ebola virus glycoprotein bound to an antibody from a human survivor. Nature 454, 177-182.

Leroy, E. M., Kumulungui, B., Pourrut, X., Rouquet, P., Hassanin, A., Yaba, P. Délicat, A., Paweska, J. T., Gonzalez, J. P., and Swanepoel, R. (2005). Fruit bats as reservoirs of Ebola virus. Nature 438, 575-576.

Leroy, E. M., Rouquet, P., Formenty, P., Souquière, S., Kilbourne, A., Froment, J. M., Bermejo, M., Smit, S., Karesh, W., Swanepoel, R., Zaki, S. R., and Rollin, P. E. (2004). Multiple Ebola virus transmission events and rapid decline of central African wildlife. Science 303, 387-390.

Lin, G., Simmons, G., Pöhlmann, S., Baribaud, F., Ni, H., Leslie, G. J., Haggarty, B. S., Bates, P., Weissman, D., Hoxie, J. A., and Doms, R. W. (2003). Differential N-linked glycosylation of human immunodeficiency virus and Ebola virus envelope glycoproteins modulates interactions with DC-SIGN and DC-SIGNR. J. Virol. 77, 1337-1346.

Linger, R. M., Keating, A. K., Earp, H. S., and Graham, D. K. (2008). TAM receptor tyrosine kinases: biologic functions, signaling, and potential therapeutic targeting in human cancer. Adv. Cancer Res. 100, 35-83.

Manicassamy, B., Wang, J., Rumschlag, E., Tymen, S., Volchkova, V., Volchkov, V., and Rong, L. (2007). Characterization of Marburg virus glycoprotein in viral entry. Virology $358,79-88$.

Marzi, A., Akhavan, A., Simmons, G., Gramberg, T., Hofmann, H., Bates, P., Lingappa, V. R., and Pöhlmann, S. (2006). The signal peptide of the Ebola virus glycoprotein influences interaction with thecellular lectins DC-SIGN and DC-SIGNR. J. Virol. 80, 6305-6317.

Marzi, A., Gramberg, T., Simmons, G., Möller, P., Rennekamp, A. J., Krumbiegel, M., Geier, M., Eisemann, J., Turza, N., Saunier, B., Steinkasserer, A., Becker, S., Bates, P., Hofmann, H., and Pöhlmann, S. (2004). DC-SIGN and DC-SIGNR interact with the glycoprotein of Marburg virus and the $S$ protein of severe acute respiratory syndrome coronavirus. J. Virol. 78 , 12090-12095.

Marzi, A., Möller, P., Hanna, S. L., Harrer, T., Eisemann, J., Steinkasserer A., Becker, S., Baribaud, F., and Pöhlmann, S. (2007). Analysis of the interaction of Ebola virus glycoprotein with DC-SIGN (dendriticcellspecific intercellular adhesion molecule 3-grabbing nonintegrin) and itshomologue DC-SIGNR. J. Infect. Dis. 196(Suppl. 2), S237-S246.

Matsuno, K., Kishida, N., Usami, K., Igarashi, M., Yoshida, R., Nakayama, E., Shimojima, M., Feldmann, H., Irimura, T., Kawaoka, Y., and Takada, A. (2010a). Different potential of Ctype lectin-mediated entry between Marburg virus strains. J. Virol. 84, 5140-5147.

Matsuno, K., Nakayama, E., Noyori, O., Marzi, A., Ebihara, H., Irimura, T., Feldmann, H., and Takada, A. (2010b). C-type lectins do not act as functional receptors for filovirus entry into cells. Biochem. Biophys. 
Res. Commun. 403, 144-148.

Michelow, I. C., Lear, C., Scully, C., Prugar, L. I., Longley, C. B., Yantosca, L. M., Ji, X., Karpel, M., Brudner, M., Takahashi, K., Spear, G. T., Ezekowitz, R. A., Schmidt, E. V., and Olinger, G. G. (2011). High-dose mannose-binding lectin therapy for Ebola virus infection. J. Infect. Dis. 203, 175-179.

Nakayama, E., Tomabechi, D., Matsuno, K., Kishida, N., Yoshida, R., Feldmann, H., and Takada, A. (2011). Antibody-dependent enhancement of Marburg virus infection. J. Infect. Dis. 204(Suppl. 3), S978-S985.

Nakayama, E., Yokoyama, A., Miyamoto, H., Igarashi, M., Kishida, N., Matsuno, K., Marzi, A., Feldmann, H., Ito, K., Saijo, M., and Takada, A. (2010). Enzyme-linked immunosorbent assay for detection of filovirus species-specific antibodies. Clin. Vac. Immunol. 17, 1723-1728.

Nanbo, A., Imai, M., Watanabe, S., Noda, T., Takahashi, K., Neumann, G., Halfmann, P., and Kawaoka, Y. (2010). Ebola virus is internalized into host cells via macropinocytosis in a viral glycoprotein-dependent manner. PLoS Pathog. 6, e1001121. doi:10.1371/journal.ppat.1001121

Nicholson-Weller, A., and Klickstein, L. B. (1999). Clq-binding proteins and Clq receptors. Curr. Opin. Immunol. $11,42-46$.

Noda, T., Ebihara, H., Muramoto, Y., Fujii, K., Takada, A., Sagara, H., Kim, J. H., Kida, H., Feldmann, H., and Kawaoka, Y. (2006). Assembly and budding of Ebola virus. PLoS Pathog. 2, e99. doi:10.1371/journal.ppat.0020099

Olinger, G. G., Bailey, M. A., Dye, J. M., Bakken, R., Kuehne, A., Kondig, J., Wilson, J., Hogan, R. J., and Hart, M. K. (2005). Protective cytotoxic T-cell responses induced by venezuelan equine encephalitis virus replicons expressing Ebola virus proteins. J. Virol. 79, 14189-14196.

Powlesland, A. S., Fisch, T., Taylor, M. E., Smith, D. F., Tissot, B., Dell, A., Pöhlmann, S., and Drickamer, K. (2008). A novel mechanism for LSECtin binding to Ebola virus surface glycoprotein through truncated glycans. J. Biol. Chem. 283, 593-602.

Reed, D. S., and Mohamadzadeh, M. (2007). Status and challenges of filovirus vaccines. Vaccine 25, 1923-1934.

Saeed, M. F., Kolokoltsov, A. A., Albrecht, T., and Davey, R. A. (2010). Cellular entry of Ebola virus involves uptake by a macropinocytosis-like mechanism and subsequent trafficking through early and late endosomes. PLoS Pathog. 6, el001110. doi:10.1371/journal.ppat.1001110

Sanchez, A., Geisbert, T. W., and Feldmann, H. (2007). "Filoviridae: Marburg and Ebola viruses," in Fields Virology, 5th Edn, eds D. M. Knipe and P. M. Howley (Philadelphia: Lippincott-Williams \& Wilkins), 1409-1448.

Sanchez, A., Trappier, S. G., Mahy, B. W., Peters, C. J., and Nichol, S. T. (1996). The virion glycoproteins of Ebola viruses are encoded in two reading frames and are expressed through transcriptional editing. Proc. Natl. Acad. Sci. U.S.A. 93, 3602-3607.

Sanchez, A., Trappier, S. G., Stroher, U., Nichol, S. T., Bowen, M. D., and Feldmann, H. (1998). Variation in the glycoprotein and VP35 genes of Marburg virus strains. Virology 240, 138-146.

Schornberg, K., Matsuyama, S., Kabsch, K., Delos, S., Bouton, A., and White, J. (2006). Role of endosomal cathepsins in entry mediated by the Ebola virus glycoprotein. J. Virol. 80, 4174-4178.

Shimojima, M., Takada, A., Ebihara, H., Neumann, G., Fujioka, K., Irimura, T., Jones, S., Feldmann, H., and Kawaoka, Y. (2006). Tyro3 family-mediated cell entry of Ebola and Marburg viruses. J. Virol. 80, 10109-10116.

Simmons, G., Reeves, J. D., Grogan, C. C., Vandenberghe, L. H., Baribaud, F., Whitbeck, J. C., Burke, E., Buchmeier, M. J., Soilleux, E. J., Riley, J. L., Doms, R. W., Bates, P., and Pöhlmann, S. (2003a). DC-SIGN and DC-SIGNR bind Ebola glycoproteins and enhance infection of macrophages and endothelial cells. Virology 305, 115-123.

Simmons, G., Rennekamp, A. J., Chai, N., Vandenberghe, L. H., Riley, J. L., and Bates, P. (2003b). Folate receptor alpha and caveolae are not required for Ebola virus glycoprotein-mediated viral infection. J. Virol. 77, 13433-13438.

Simmons, G., Wool-Lewis, R. J., Baribaud, F., Netter, R. C., and Bates, P. (2002). Ebola virus glycoproteins induce global surface protein downmodulation and loss of cell adherence. J. Virol. 76, 2518-2528.

Sinn, P. L., Hickey, M. A., Staber, P. D., Dylla, D. E., Jeffers, S. A., Davidson, B. L., Sanders, D. A., and McCray, P. B. Jr. (2003). Lentivirus vectors pseudotyped with filoviral envelope glycoproteins transducer airway epithelia from the apical surface independently of folate receptor alpha. J. Virol. 77 , 5902-5910.

Subbotina, E., Dadaeva, A., Kachko, A., and Chepurnov, A. (2010). Genetic factors of Ebola virus virulence in guinea pigs. Virus Res. 153, 121-133.

Sullivan, N. J., Geisbert, T. W., Geisbert, J. B., Shedlock, D. J., Xu, L., Lamoreaux, L., Custers, J. H., Popernack, P. M., Yang, Z. Y., Pau, M. G., Roederer, M., Koup, R. A., Goudsmit, J., Jahrling, P. B. and Nabel, G. J. (2006). Immune protection of nonhuman primates against Ebola virus with single lowdose adenovirus vectors encoding modified GPs. PLoS Med. 3, e177. doi:10.1371/journal.pmed.0030177

Sullivan, N. J., Geisbert, T. W., Geisbert, J. B., Xu, L., Yang, Z. Y., Roederer, M., Koup, R. A., Jahrling, P. B., and Nabel, G. J. (2003). Accelerated vaccination for Ebola virus hamorrhagic fever in non-human primates. Nature 424, 681-684.

Sullivan, N. J., Sanchez, A., Rollin, P. E., Yang, Z. Y., and Nabel, G. J. (2000). Development of a preventive vaccine for Ebola virus infection in primates. Nature 408, 605-609.

Takada, A., Ebihara, H., Feldmann, F., Geisbert, T. W., and Kawaoka, Y. (2007). Epitopes required for antibody-dependent enhancement of Ebola virus infection. J. Infect. Dis. 196(Suppl. 2), S347-S356.

Takada, A., Feldmann, H., Ksiazek, T. G., and Kawaoka, Y. (2003a). Antibody-dependent enhancement of Ebola virus infection. J. Virol. 77, 7539-7544.

Takada, A., Feldmann, H., Stroeher, U., Bray, M., Watanabe, S., Ito, H., McGregor, M., and Kawaoka, Y. (2003b). Identification of protective epitopes on Ebola virus glycoprotein at the single amino acid level by using recombinant vesicular stomatitis viruses. J. Virol. 77, 1069-1074.

Takada, A., Fujioka, K., Tsuiji, M., Morikawa, A., Higashi, N., Ebihara, H., Kobasa, D., Feldmann, H., Irimura, T., and Kawaoka, Y. (2004). Human macrophage Ctype lectin specific for galactose and $N$-acetylgalactosamine promotes filovirus entry. J. Virol. 78 2943-2947.

Takada, A., and Kawaoka, Y. (2001). The pathogenesis of Ebola hemorrhagic fever. Trends Microbiol. 9, 506-511.

Takada, A., and Kawaoka, Y. (2003). Antibody-dependent enhancement of viral infection: molecular mechanisms and in vivo implications. Rev. Med. Virol. 13, 387-398.

Takada, A., Robison, C., Goto, H. Sanchez, A., Murti, K. G., Whitt, M.
A., and Kawaoka, Y. (1997). A system for functional analysis of Ebola virus glycoprotein. Proc. Natl. Acad. Sci. U.S.A. 94, 14764-14769.

Takada, A., Watanabe, S., Okazaki, K., Kida, H., and Kawaoka, Y. (2001). Infectivity-enhancing antibodies to Ebola virus glycoprotein. J. Virol. 75, 2324-2330.

Towner, J. S., Amman, B. R., Sealy, T. K., Carroll, S. A., Comer, J. A., Kemp, A., Swanepoel, R., Paddock, C. D., Balinandi, S., Khristova, M. L., Formenty, P. B., Albarino, C. G., Miller, D. M., Reed, Z. D., Kayiwa, J. T., Mills, J. N., Cannon, D. L., Greer, P. W., Byaruhanga, E., Farnon, E. C., Atimnedi, P., Okware, S., KatongoleMbidde, E., Downing, R., Tappero, J. W., Zaki, S. R., Ksiazek, T. G., Nichol, S. T., and Rollin, P. E. (2009). Isolation of genetically diverse Marburg viruses from Egyptian fruit bats. PLoS Pathog. 5, e1000536. doi:10.1371/journal.ppat.1000536

Towner, J. S., Sealy, T. K., Khristova, M. L., Albariño, C. G., Conlan, S., Reeder, S. A., Quan, P. L., Lipkin, W. I., Downing, R., Tappero, J. W., Okware, S., Lutwama, J., Bakamutumaho, B., Kayiwa, J., Comer, J. A., Rollin, P. E., Ksiazek, T. G., and Nichol, S. T. (2008). Newly discovered Ebola virus associated with hemorrhagic fever outbreak in Uganda. PLoS Pathog. 4, e1000212. doi:10.1371/journal.ppat.1000212

Usami, K., Matsuno, K., Igarashi, M., Denda-Nagai, K., Takada, A., and Irimura, T. (2011). Involvement of viral envelope GP2 in Ebola virus entry into cells expressing the macrophage galactose-type C-type lectin. Biochem. Biophys. Res. Commun.407, 74-78.

Volchkov, V. E., Chepurnov, A. A., Volchkova, V. A., Ternovoj, V. A., and Klenk, H. D. (2000). Molecular characterization of guinea pig-adapted variants of Ebola virus. Virology 277, 147-155.

Volchkov, V. E., Feldmann, H., Volchkova, V. A., and Klenk, H. D. (1998). Processing of the Ebola virus glycoprotein by the proprotein convertase furin. Proc. Natl. Acad. Sci. U.S.A.95, 5762-5767.

Warfield, K. L., Bradfute, S. B., Wells, J., Lofts, L., Cooper, M. T., Alves D. A., Reed, D. K., VanTongeren, S. A., Mech, C. A., and Bavari, S. (2009). Development and characterization of a mouse model for Marburg hemorrhagic fever. J. Virol. 83, 6404-6415.

Weissenhorn, W., Carfí, A., Leem, K. H., Skehelm, J. J., and Wiley, D. C. (1998). Crystal structure of the 
Ebola virus membrane fusion subunit, GP2, from the envelope glycoprotein ectodomain. Mol. Cell 2, 605-616.

Wool-Lewis, R. J., and Bates, P. (1998). Characterization of Ebola virus entry by using pseudotyped viruses: identification of receptor-deficient cell lines. J. Virol. 72, 3155-3160.

Yang, Z. Y., Duckers, H. J., Sullivan, N. J., Sanchez, A., Nabel, E. G., and
Nabel, G. J.(2000). Identification of the Ebola virus glycoprotein as the main viral determinant of vascular cell cytotoxicity and injury. Nat. Med. 6, 886-889.

Conflict of Interest Statement: The author declares that the research was conducted in the absence of any commercial or financial relationships that could be construed as a potential conflict of interest.

Received: 24 December 2011; paper pending published: 11 January 2012; accepted: 19 January 2012; published online: 06 February 2012

Citation: Takada A (2012) Filovirus tropism: cellular molecules for viral entry. Front. Microbio. 3:34. doi 10.3389/fmicb.2012.00034
This article was submitted to Frontier in Virology, a specialty of Frontiers in Microbiology.

Copyright (C) 2012 Takada. This is an open-access article distributed under the terms of the Creative Commons Attribution Non Commercial License, which permits non-commercial use, distribution, and reproduction in other forums, provided the original authors and source are credited. 